\title{
Studying on the Decoration of Western Sichuan Folk Dwellings under the Influence of Taoist Culture*
}

\author{
Wenfeng Xie \\ College of Landscape Architecture \\ Sichuan Agricultural University \\ Chengdu, China 611130
}

Xingyu Bao

College of Landscape Architecture

Sichuan Agricultural University

Chengdu, China 611130

Meiqi Zhao

College of Landscape Architecture

Sichuan Agricultural University

Chengdu, China 611130

\author{
Zhidan Luo \\ College of Landscape Architecture \\ Sichuan Agricultural University \\ Chengdu, China 611130
}

\author{
Runan Dai \\ College of Landscape Architecture \\ Sichuan Agricultural University \\ Chengdu, China 611130 \\ Yumei Huang** \\ College of Landscape Architecture \\ Sichuan Agricultural University \\ Chengdu, China 611130 \\ **Corresponding Author
}

\begin{abstract}
Starting from the analysis of Taoist culture and thought contained in the gatehouse decoration of west Sichuan folk dwelling houses, this paper explores the integration of form and content of Taoist aesthetic appreciation and imagery. Furthermore, through the investigation on gatehouse decoration of Liu's manor architectural complex, this paper summarizes manifestation form of traditional gatehouse decoration art of Liu's manor under the cultural connotation of Taoism, which has positive significance to modern folk dwellings design.
\end{abstract}

Keywords-Taoist culture; western Sichuan folk dwelling houses; Liu's manor; gatehouse decoration

\section{INTRODUCTION}

The Western Sichuan takes the Chengdu plain as the center, and is surrounded by mountains and hills. The natural geographical condition is superior. This piece of fertile land, which is based on Qingcheng Mount, breeds unique cultural landscapes and folk customs. Since Ling Zhang, the founder of Tianshi Taoism, has opened the Taoist fairy source here, the track of immortals and Taoist activities are frequent, so Taoism is also widely spread in the Western Sichuan. As a carrier of local historical culture and people's spiritual life, the long-lasting Taoism culture has a significant influence on the construction of the dwellings in the Western Sichuan. The gatehouse is one of the important components of the Western Sichuan folk house. The local people, both the rich and the poor, love to make some decorations on the gatehouse. It can make it more beautiful and contain rich cultural connotation of

* Fund projects: special achievements in social science research of agriculture in Sichuan.
Taoism.

\section{The Gatehouse Decoration ART OF ResidentiaL} BUILDINGS IN WESTERN SICHUAN UNDER THE INFLUENCE OF TAOIST CULTURE

In many cultural impacts, the image aesthetics in Taoist aesthetics has the most direct impact on the decoration of the gatehouses in Western Sichuan. The Book of Changes - Xici Shangzhuan said: "there are four ways of the saints': speakers pay attention to words; doers pay attention to changes of situation; craftsmen stress to get enlightenment from daily things; diviners attach importance to divination methods". The idea of craftsmanship has laid an important foundation for the image aesthetic of architectural decoration art. "The saints erect the images of the hexagrams to fully express the meaning with the method of symbol and set lines and hexagrams to explain the authenticity of all things on earth", which gives men enlightenment. The content of hexagram images is expanded rich physical images from original forms, and physical images are transformed to art and then form into interior image by sense of organs [1]. So, building is regarded as art craft, and all things on earth are images. In the construction and decoration of building, observe things on earth and materialize their images, and then express them in the form of art. Transmit it by people's psychology and sense, and finally reach the blend of love and scenery, which is also the essence of modern design.

Taoism advocates the essence of "simplicity" and "authenticity", and advocates the unity of heaven, earth and man, which are the highest standards of nature, and the thought 
of "harmony between heaven and man" should be felt by man and nature. It is a true reflection of Taoism to draw inspiration from all things on earth and to apply these natural themes to the gatehouse decoration in Western Sichuan.

\section{The GATEHOUSE DECORATION ART OF LIU'S MANOR}

Liu's manor, located in Dayi County, Sichuan Province, is one of the best preserved feudal landlord manors in the country, about fifty kilometers from Qingcheng Mount, built in the late Qing Dynasty and completed in the end of the Republic of China. The owner of the manor was the famous Liu family at that time. The whole family was full of legends because of appearance of large numbers of bureaucrats, grasping absolute

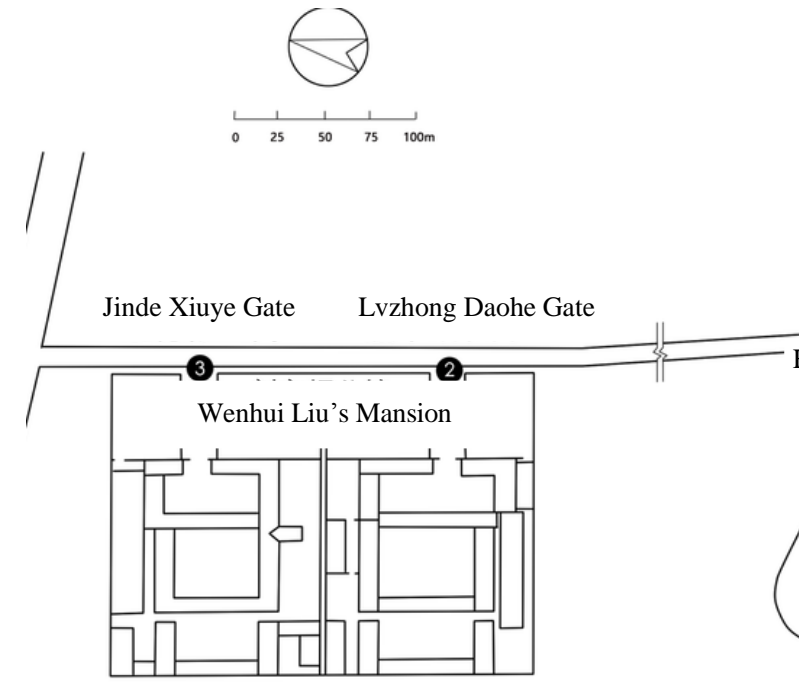

Fig. 1. The plan of Liu's Manor in Dayi (self-drawing).

The gatehouse decoration of Liu's manor is guided by the spiritual connotation and aesthetic thought of Taoism to a great extent. However, because of the identity and pursuit of the owners of the houses in the manor, their outlook on life, morality and art are also quite different, and everyone was more inclined to think in the spirit of Taoism suitable for themselves. Therefore, even the same Taoist philosophy has different effects on different people. The gate building of Liu's manor mainly uses four kinds of decoration, including plaque art, sculpture art, relief art and painting art, to show the combination of image and connotation and the desire demand of house owners.

\section{A. The Art of Plaque}

The inscribed board mainly displays the unique concept, consciousness and belief of the owner through words, and expresses the meaning of the building that the builder of the house is unable to express, and its content is also in the Taoist culture.

The gate of old mansion has a plague of "Hengyan Lvyang" ("Fig. 2"), which is a charming picture of the pastoral power in Chuankang and extreme richness. The Liu's ancestral house and old mansion at the south are main part of the whole building, and the new mansion is located at the north (Fig. 1). The new and old mansions were the residences of Wenhui Liu, the great warlord, and Wencai Liu, the great landlord. The manor building has a large scale, of which only the mansion of Wencai Liu covers a building area of more than 10000 square meters. There are 27 large and small courtyards, 3 gardens and 7 gates [2]. The architectural construction of Liu's manor truly reflects the unique architectural skill of residential buildings in Western Sichuan, and the deep influences of Taoist cultural thought on all aspects of people's life in the Western Sichuan area. The exquisite decoration of gatehouse, superb skills and rich connotation of the buildings are extraordinary.

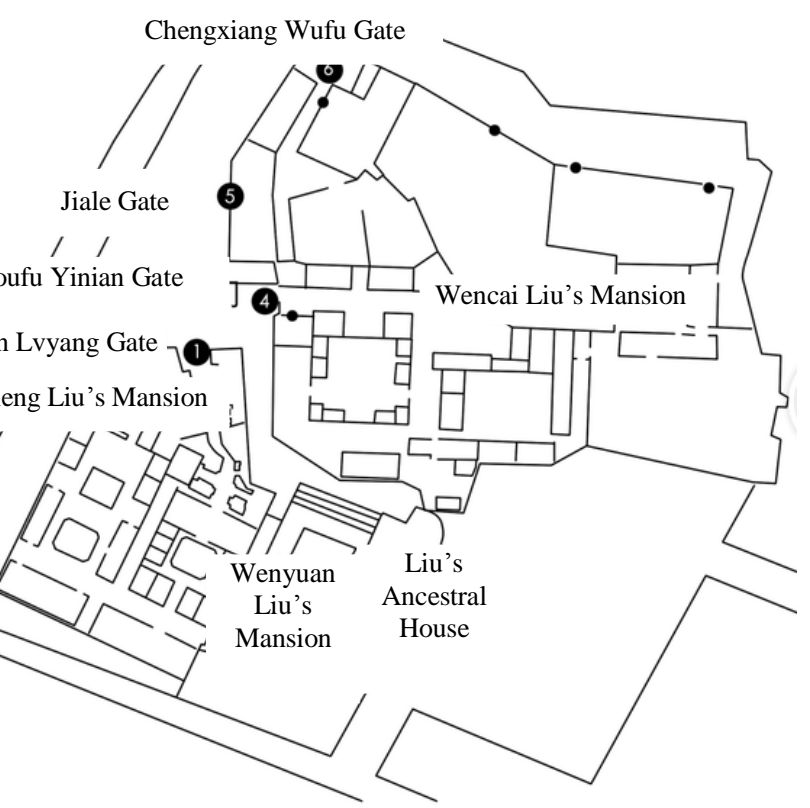

scenery before the gate of the mansion in those days. Lao Tzu once put forward the spirit of "following the nature" and "return to nature". A good natural environment can realize the harmonious symbiosis between nature and man, so people yearn for the geomantic treasure land that is secluded and steep, and surrounded by mountains and rivers. The two gateways of the new mansion are "Jinde Xiuye" (Fig. 3) gate and "Lvzhong Daohe" gate (Fig. 4). "Jinde Xiuye" originates from Book of Changes . Qian. It says: "Junzi Jinde Xiuye". It means gentleman should build moral characters and make achievements. This plague is motivational, showing the master's constant pursuit of morality and cause. "Lvzhong Daohe" expresses a meaning of "harmony is previous". The old mansion is the house of landlord Wencai Liu, and the plague of its gatehouse is "Shoufu Yinian" (Fig. 5), which means to receive the blessing of harvest year from god. The texts are simple, but it is enough to give people a more accurate judgment on the owners of houses. The plague of the new mansion has given the best wishes to the whole family. The old mansion is more vulgar in both the plaque and the decorative style. It shows they want to be rich, live long and have a happy family. 


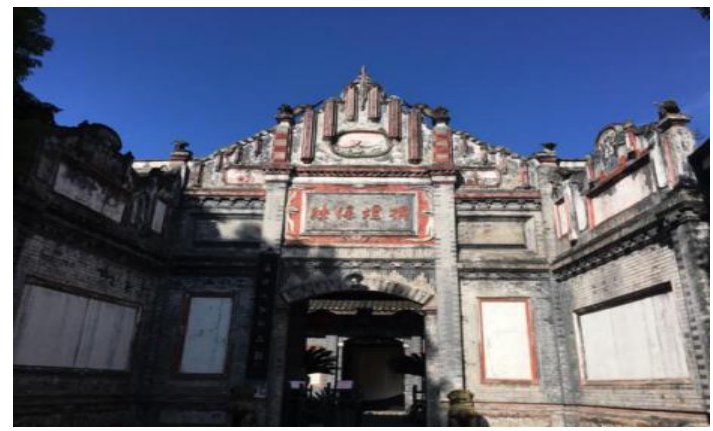

Fig. 2. "Hengyan Lvyang” gate (self photography).

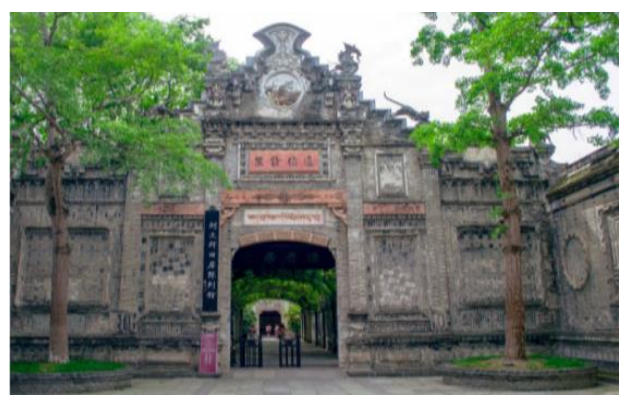

Fig. 3. "Jinde Xiuye" gate (self photography).

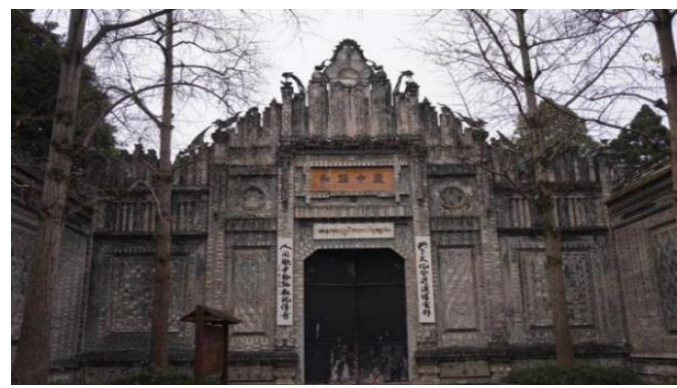

Fig. 4. "Lvzhong Daohe” gate (self photography).

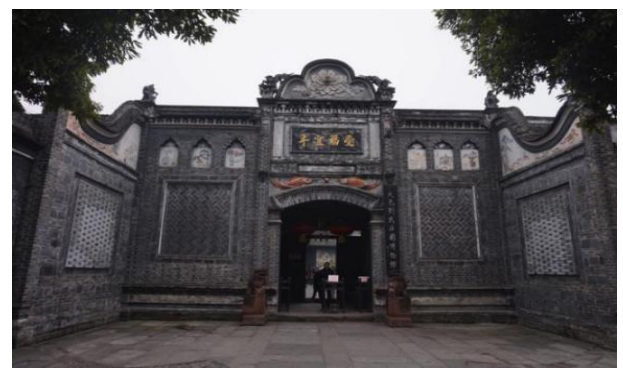

Fig. 5. "Shoufu Yinian” gate (self photography).

\section{B. Round Sculpture Art}

The art of round sculpture mainly uses grey plastic technique. This technique was originally a decorative craft of traditional architecture in the south of the Five Ridges. It was the most popular in the Ming and Qing Dynasties. It was often seen in the temples and houses of rich family, and was also widely used in folk dwellings of Western Sichuan in the Republic of China [3]. Sichuan is one of the main origin places of limestone. The grey plastic reflects the people's best use of local materials, and has achieved good economic and artistic effects. At the same time, the use of natural materials also embodies the idea of returning to nature and integrating with nature in Taoist culture.

In the manor, the decorations on the gates of the new mansion are most diverse. Twenty beasts are placed on the gate of "Jinde Xiuye". The number of sculptures is the most compared with that of other mansions in the manor. Among them the typical images are Kirin, tigers, lions and deer. Kirin has dragon head, horse body and dragon scale in one. Tail hair is stretched like dragon tail, having a symbol of peace and long life. It is the king of auspicious beasts, and symbolizing a prosperous government. It can bring wealth and blessings, remove misfortunes and bring children for the family, so it is the beat beast for folk dwelling to protect the house and bring good fortune[4]. Tiger ("Fig. 6") represents justice and valor. In ancient time people often said immortals took a tiger and went up to heaven. Lion was regarded as the king of animal, and is a symbol of right and power. Chuan Deng Lu records: lion roared: "I am the most respectable from the heaven and earth". The lion roared and other beasts responded. In geomancy, lion can avoid evil, bring auspiciousness, and remove adversities. It can strengthen the Yang Qi of governmental power and house owner. Deer ("Fig. 7") was often regarded as mount of immortals. Deer boy and crane fairy are close disciples of the Old Man of South Pole, and often represents health and longevity.

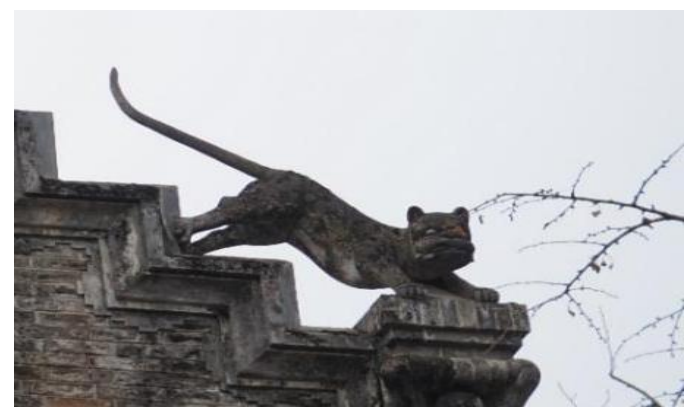

Fig. 6. Sculpture of tiger (self photography).

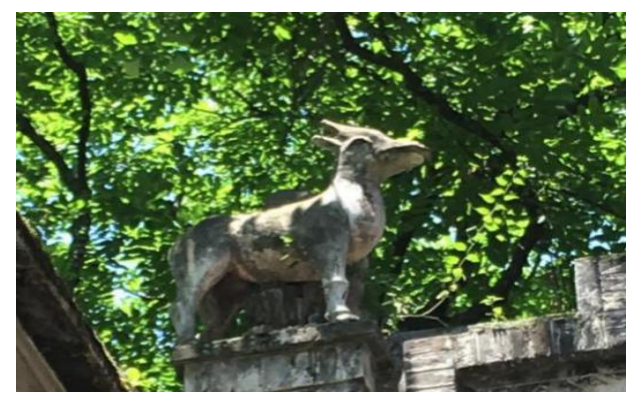

Fig. 7. Sculpture of deer (self photography).

The round sculptures on gatehouse of the new mansion are dominated by celestial animals, and its interior sculptures of the gatehouse are mostly based on natural plant themes (Fig. 8 and Fig. 9). For example, pumpkin has many seeds, luxuriant cirrus and sweet fruit pulp. So, it is a symbol of having many sons and grandsons, good fortunes and happy life in Taoist culture. The partial tone of “白菜” (bái cài) is “百财”(bái cái), meaning all kinds of wealth. These sculptures not only merge 
into the daily life of the common people, but also conform to the thought of "follow the nature" advocated by Lao Tzu, which embodies the realm of originating from nature but higher than nature in the design.

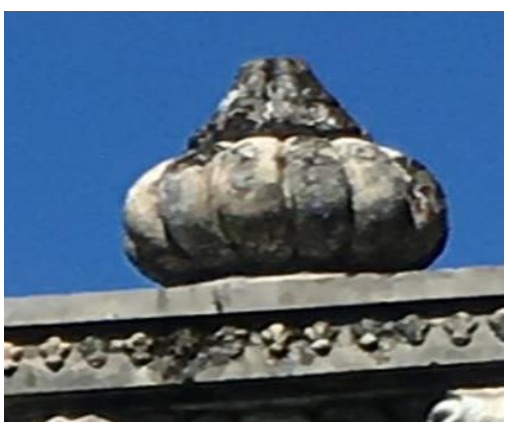

Fig. 8. Sculpture of pumpkin (self photography).

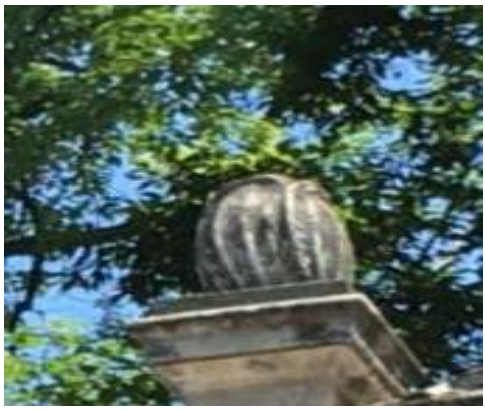

Fig. 9. Sculpture of Chinese cabbage (self photography)

\section{Relief Art}

The gray plastic relief is a semi-solid sculpture, which is more exquisite and gorgeous than other decorative types. The embossing and protruding are natural, with the sense of harmony between yin and Yang in Taoism. The most distinctive relief in the manor is the miss's hall, which is not only exquisite in skill, smooth in line and hook face, and rich in carving layer, but also achieves perfect unity in technology and art, content and form. The huge peony on the top of "Xiangcheng Wufu" gate (Fig. 10), the relief pattern is rich and full, suitable for family belonging of wood and fire. From the geomantic omen layout of the old mansion, the miss's hall is located at the xun southeast position, representing the status of elder daughter belonging to wood in the family. At the same time, the peony on the top of gatehouse of miss's hall sets off each other with the peony on the top of "Shoufu Yinian" gate in emotion.

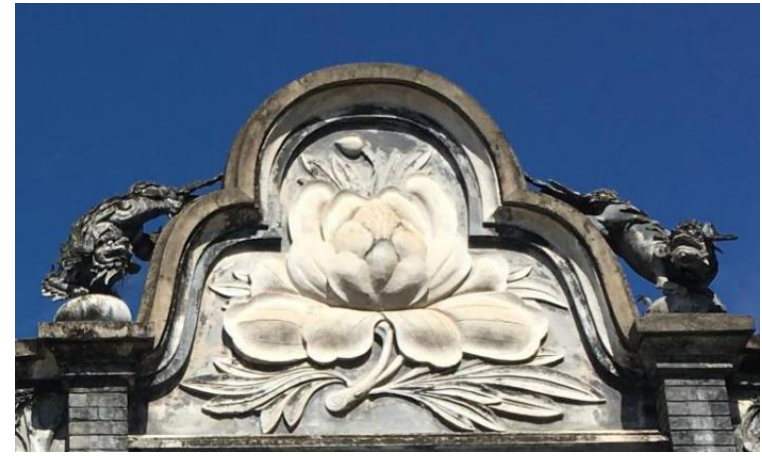

Fig. 10. Peony relief (self photography).

\section{Painting Art}

On the gatehouse of the old house are six flat paintings ("Fig. 11"), which are on the theme of implements. From the left to the right respectively are vase with peacock feathers and red coral bonsai, Ruyi bonsai with a greeting pine, vase with peony and plum flower, grape fruit box and vase with persimmon branch, Ruyi clivia bonsai, the Maitreya Buddha and the peony bonsai.

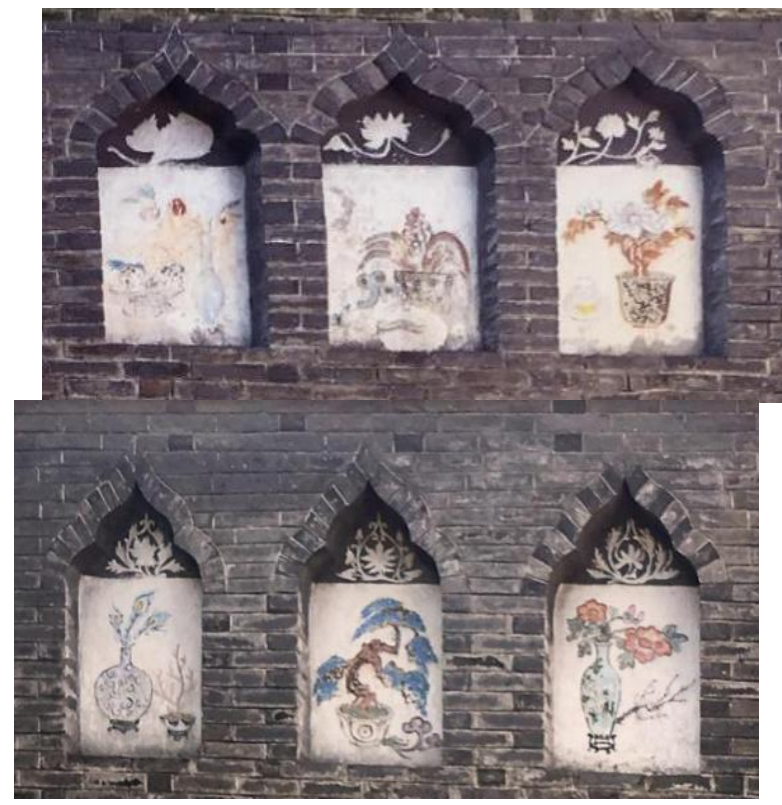

Fig. 11. Paintings on the gate of "Shoufu Yinian" gate (self photography).

These various decorative themes are the embodiment of Taoist imagery aesthetics. The peacock feathers are the expectation of the family's auspiciousness and happiness. The red coral bonsai is like "fortune tree" in form, and is called "auspicious treasure", and is the symbol of eternality and nobility. The gesture of greeting pine is vigorous and forceful, refined and courteous, just like an appearance of the master opening up to greet guests from the world. Vase and box have the partial tones of “ $\mathrm{He}($ 和)" and “Ping(瓶-vase)" are similar with "He( 合 -harmony)" and "Ping( 平-peace)", meaning "harmony" and "peace"[5]. "Shi(柿-persimmon)" has the partial tone of "Shi(事-things)", so persimmon vase means everything is safe. Grape has many seeds and far-flung 
branches, so it has the meaning of continuous sons and grandsons and prosperous family. Clivia is an extremely spiritual plant in Taoist culture. It can perceive the invasion of Yin Qi, and effectively make up for the deficiency of power of the five elements and change the bad atmosphere of the family and make the family harmonious. The flower, like its name, symbolizes quietness and elegance, strong and resolute character, and is very suitable for the decoration of gatehouse. These implied that Wencai Liu also valued his family and even the whole large family in a traditional Chinese way, just like other ordinary people.

\section{CONCLUSION}

The residential buildings in Western Sichuan are not only the carrier of local traditional culture, but also the comprehensive reflection of local traditional culture. The Taoist cultural connotation contained in the decoration of Liu's manor in Dayi embodies the perfect combination of Taoist aesthetic design thought and the decoration of the gatehouse in Western Sichuan. It shows the identity and status of the master and the good wishes for the longevity. It is worth the use of the materials from the folk and daily life to carry forward the traditional cultural techniques in the design of modern residential buildings.

\section{REFERENCES}

[1] Xingli Li. Study on the Architectural Art of Taoist Temple in Sichuan. Chengdu: Bashu Publishing House, 2015. 李星丽.四川道教宫观建筑 艺术研究[M].成都: 巴蜀书社, 2015.

[2] Chengcai Wang. Rich Family and Private Residence: Taste Liu's Manor West China.2004 (3): 92-95. 王成才.豪门与民居:品味刘氏庄园[J].中 国西部.2004(3):92-95

[3] Zhiwei Wu, Ren An: one town and 27 mansions. China National Geographic, 2014 (4): 56-70,72-77. 吴志维.安仁:1 个小镇, 27 座公馆 [J].中国国家地理,2014（4）:56-70,72-77

[4] Jianhua Wang. Auspicious Decoration Meanings of Ancient Architecture in Shanxi. Taiyuan: Shanxi People's Publishing House, 2014. 王建华. 山西古建筑吉祥装饰寓意 [M].太原: 山西人民出版 社,2014.

[5] Guoxiao Song. Auspicious Decoration of Chinese Ancient Architecture. Beijing: China Water Conservancy and Hydropower Press, 2008. 宋国 晓.中国古建筑吉祥装饰[M]. 北京: 中国水利水电出版社, 2008 